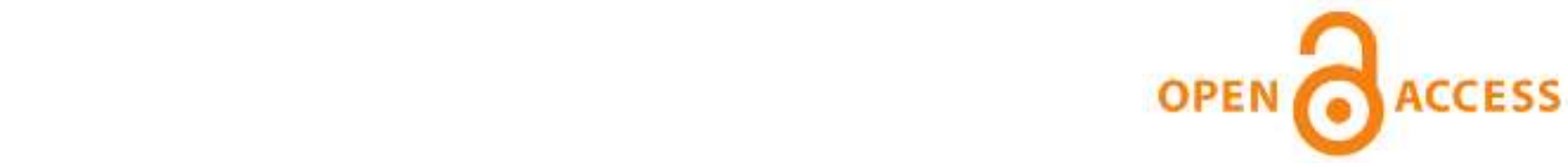 \\ International Journal of Social Sciences and Management \\ A Rapid Publishing Journal
}

ISSN 2091-2986

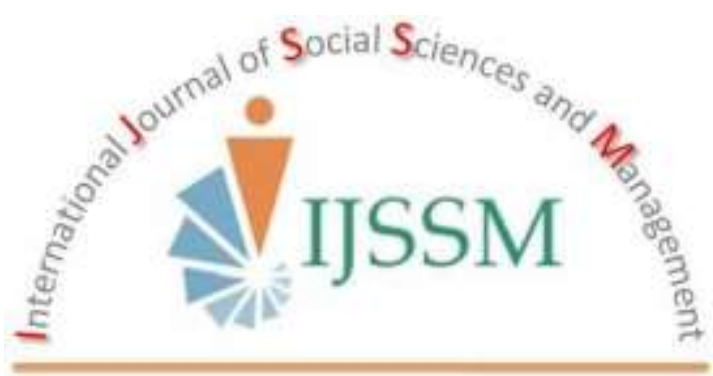

\section{Indexing and Abstracting}

CrossRef, Google Scholar, International Society of Universal Research in Sciences (EyeSource), Journal TOCs, New Jour, Scientific Indexing Services, InfoBase Index, Open Academic Journals Index (OAJI), Scholarsteer, Jour Informatics, Directory of Research Journals Indexing (DRJI), International Society for Research Activity (ISRA): Journal Impact Factor (JIF), Simon Fraser University Library, etc.

Vol- 2(4), October 2015 


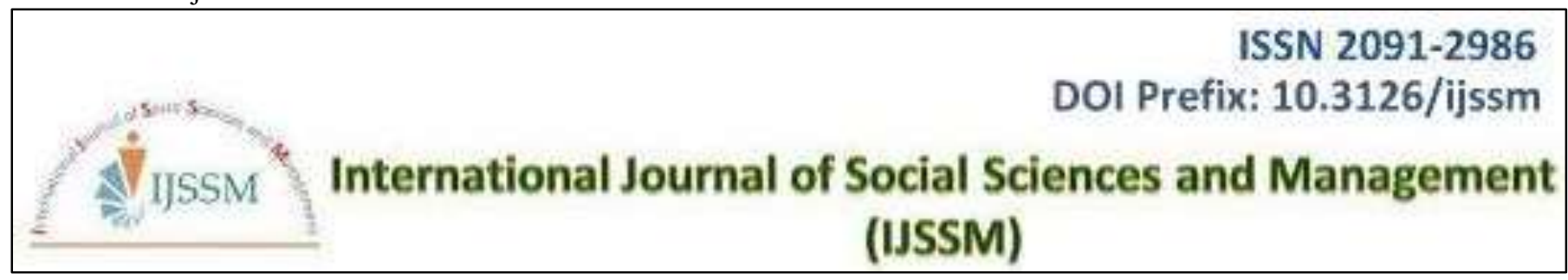

\title{
Research Article \\ IMPACT OF NAVRATRAS FESTIVAL ON THE SUBJECTIVE WELL BEING OF VEGETARIAN CUSTOMERS IN HOSPITALITY SECTOR
}

\author{
Arvind K Birdie* \\ IIMT School of Management, Oxford Brooks University, Vedatya Institute, Gurgaon, India \\ *Email: arvindgagan@gmail.com
}

\begin{abstract}
Festivals are part of living in India and are known for bringing upliftment in moods and well beings of individuals. With the changing lifestyle in metros, young generations are in transition of adopting new modern cultural and food habits such as dining out. The present paper studies the impact of Navratras festival on subjective wellbeing of vegetarian customers in fast food joints and hotels. The paper employed a survey research design and convenient critical analysis from vegetarian customers and hoteliers. The sample (N250) was customers in all categories hotels and fast food joints in Delhi NCR. Data was collected using questions adapted from standardized tool of Sell and Nagpal's The Subjective Wellbeing Inventory (1992) and an interview schedule was adopted. Findings revealed that celebrating Navratras outside reflects changing life style and has a positive impact on customers' subjective wellbeing.
\end{abstract}

Keywords: Navratras; Subjective Wellbeing; Vegetarian customers; hospitality sector.

\section{Introduction}

Festivals are always meant to fulfill our social needs of belongingness since old days. Since India has rich culture and heritage of celebrating various festivals, communities and individuals used it for developing social interactions and especially for women and children it was a mean of emotional catharsis that helped them for emotionally and psychologically venting their emotions. Navratri is an important festival and is celebrated all over India. As Indian population is mostly Hindu by religion, it is usually important for the devotees to be vegetarian on 9 days. The dates of the festival are determined according to the lunar calendar on which each women follow tradition to wear nine colors of dress on Navratri.

Navaratri is celebrated in different ways throughout India. In North India, all three Navaratris are celebrated with much fervor by fasting on all nine days and worshiping the Mother Goddess in her different forms. The ChaitraNavratri culminates in Ram Navami and the Sharad Navaratri culminates in Durga Puja and Dusshehra.

In Western India, particularly in the state of Gujrat and Mumbai, Navratri is celebrated with the famous Garba and Dandiya-Raas dance. Since the past few years, the Government of Gujarat has been organising the "Navratri Festival Celebrations" on a regular basis for the nine days of Navratri Festival in Gujarat.

In Karnataka, Ayudha Puja, the ninth day of Mysore Dasara, is celebrated with the worship of implements used in daily life such as computers, books, vehicles, or kitchen tools. It is believed that any new venture such as starting of business or purchasing of new household items on this day is bound to bring success and prosperity. In Kerela and in some parts of Karnataka three days: Ashtami, Navami, and VijayDashami of SharadNavarathri are celebrated as Sarasvati Puja in which books are worshiped. In Telengana region of Andhra Pradesh, people celebrate Bathukamma festival over a period of nine days. It is a kind of navratri celebration.

During Navratri, some devotees of Durga observe a fast and prayers are offered for the protection of health and prosperity. Devotees avoid meat, alcoholic drinks, grains, wheat and onion during this fast. Grains are usually avoided since it is believed that during the period of Navratri and seasonal change, grains attract and absorb lots of negative energies from the surrounding and therefore there is a need to avoid eating anything which are produced from grains for the purification of Navratri to be successful. Navratri is also a period of introspection and purification, and is traditionally an auspicious and religious time for starting new ventures.

During the eighth or ninth day, Kanya Puja, pre-pubescent girls are ceremonially worshipped.

Most people confine themselves to fruit during the nine days/nights. Most devotees take a single meal during the day/night, and non-vegetarian food is avoided. Also, the consumption of onion and garlic is avoided for the entire duration of Navaratri. During navratri generally special vegetarian dishes are served which are Makhane Ki Sabzi, SawankKeChawal, DahiPudine Wale Aloo, Shakarkandi Ki Chaat, SabudanaPapad, Banana Raita, AlooRaita, SinghareKePakode, Banana Chips, KadduKaRaita, Malaiwale-Kofte. 
As non-vegetarian dishes are avoided by customers of hotels and more people opt for vegetarian dishes during Navratras festival, Hotels and fast food joints in recent years came up with various new dishes for their customers besides regular "vegetarian thalis".

According to Royal China, Director, Relan, (IANS, 2014), The fine dining Chinese cuisine restaurant decided to start special menus for the Hindu festival as they believe that most Delhities turn vegetarians during this period. "The festival is a big one which is mostly celebrated in Delhi. Eighty percent of people become vegetarians for these nine days. We thought of giving more options to our customers and so came up with this special menu," said Relan

Festivals bring cohesion among individuals, families and communities and acts as source for belongingness and a sense of purpose in the lives.

Subjective well-being refers to how people experience and evaluate their lives and specific domains and activities in their lives. This information has already proven valuable to researchers, who have produced insights about the emotional states and experiences of people belonging to different groups, engaged in different activities, at different points in the life course, and involved in different family and community structures. Research has also revealed relationships between people's self-reported, subjectively assessed states and their behavior and decisions. (Stone and Mackie, 2013)

Psychologists have defined happiness as a combination of life satisfaction and the relative frequency of positive and negative affect. Subjective Well Being SWB therefore encompasses moods and emotions as well as evaluations of one's satisfaction with general and specific areas of one's life. Concepts encompassed by SWB include positive and negative affect, happiness and life satisfaction.

There are 2 components of SWB. One is Affect Balance and the other is Life Satisfaction.

Affect balance refers to the emotions, moods, and feelings a person has. Affective concepts of SWB can be considered in terms of momentary emotional states as well as in terms of longer-term moods and tendencies (i.e. how much positive and/or negative affect a person generally experiences over any given period of time).

The term "happiness" is also commonly used in regards to SWB and has been defined variously as "satisfaction of desires and goals" (therefore related to life satisfaction), as a "preponderance of positive over negative affect" (therefore related to emotional components of SWB), as "contentment" and as a "consistent, optimistic mood state" and may imply an affective evaluation of one's life as a whole. Life satisfaction can also be known as the "stable" component in one's life.

A person's level of subjective well-being is determined by many different factors and social influences prove to be a strong one. Results from the famous Framingham Heart Study indicate that friends three degrees of separation away (that is, friends of friends of friends) can affect a person's happiness. From abstract: "A friend who lives within a mile (about $1.6 \mathrm{~km}$ ) and who becomes happy increases the probability that a person is happy by $25 \%$."

\section{Cultural Variations}

Although all cultures seem to value happiness, cultures vary in how they define happiness.

In Western cultures, predictors of happiness include elements that support personal independence, a sense of personal agency, and self-expression. In Eastern cultures, predictors of happiness focus on an interdependent self that is inseparable from significant others. Compared to people in individualistic cultures, people in collectivistic cultures are more likely to base their judgments of life satisfaction on how significant others appraise their life than on the balance of inner emotions experienced as pleasant versus unpleasant. Pleasant emotional experiences have a stronger social component in East Asian cultures compared to Western ones.

With the changing lifestyle and working population residing in Delhi NCR and changing culture of generations becoming more cosmopolitan in their lives and food habits, the impact of Navratras on subjective wellbeing of today's generation was studied.

This area in tourism and subjective wellbeing is a valuable, novel intervention worthy of exploration. Engagement is one key measure in positive psychology.

Keeping in view the above perspective of busy $24 \times 7$ life of young corporate who are regular customers of hospitality industry, researchers took initiative to study the impact of this big and long duration Navratra festival on the subjective wellbeing of vegetarian customers.

\section{Review Literature}

Research has shown that festival attendance can create a sense of community, bringing groups together beyond the mere aggregate of people; a sense of common purpose and connection can emerge (Gibson and Connell, 2003).Martin Seligman, the father of modern positive psychology, emphasizes the importance of wellbeing, and suggests five quantifiable measures to reflect this construct. They are referred to by the acronym PERMA: Positive Emotion, Engagement, Positive Relationships, Meaning, and Accomplishment (Seligman, 2011).

Improving measures like engagement is key to improve wellbeing. Low levels of wellbeing are costly to an individual's health, social interactions, and daily life, and also in terms of economy and productivity for society and organization (Fredrickson and Losada, 2005).

Research has shown that festival attendance can create a sense of community, bringing groups together beyond the mere aggregate of people; a sense of common purpose and connection can emerge (Gibson and Connell, 2003).

Australian researchers Packer and Ballantyne (2010) investigated the social wellbeing and psychological benefits 
of music festival attendance in a sequential, mixed-methods exploratory study. They reported that people experience senses of engagement and connection at festivals in ways that are not possible in even typical live music concerts. Not only is there much interaction with other attendees, especially in the context of multi-day events, but with artists themselves; the music festival allows for close proximity (Harrison, 2014).

Martin Seligman, the father of modern positive psychology, emphasizes the importance of wellbeing, and suggests five quantifiable measures to reflect this construct. They are referred to by the acronym PERMA: Positive Emotion, Engagement, Positive Relationships, Meaning, and Accomplishment (Seligman, 2011).

This area in tourism and subjective wellbeing is a valuable, novel intervention worthy of exploration. Engagement is one key measure in positive psychology.

Improving measures like engagement is key to improve wellbeing. Low levels of wellbeing are costly to an individual's health, social interactions, and daily life, and also in terms of economy and productivity for society and organization (Fredrickson and Losada, 2005).

The individual is defined as a part of a larger social network rather than as anique and separate entity in collectivist cultures like India.

A fascinating picture of subjective wellbeing is emerging in which we can differentiate between a person's momentary feelings and thoughts about wellbeing and larger, more global constructions (Diener et al., 2002).

The existence of a positive relationship between spiritual engagement and well-being is currently based on weak correlational evidence, generally in Western contexts. The study by Mellor et al. (2012), advanced the understanding through a naturalist, longitudinal study of 226 people, including Malays, Chinese, and Indians, experiencing the Hindu Thaipusam festival in Malaysia. They measured the subjective well-being of people with varying levels of engagement-from nonobservance or simply observing the festival to extreme engagement. Each person was assessed 3 months before, 2 weeks before, 2 weeks after, and 4 months after the festival. They found that the subjective well-being of those with the most extreme level of engagement was permanently higher than other groups. The well-being of those with a strong, but less extreme engagement rose at the time of the festival and remained elevated.

Brow et al. (2013) investigated the possible relationship between two spirituality variables (religious coping styles and spiritual well-being) and two psychological variables (anxiety and depression). Also studied were differences between those who self-disclosed a spiritual/religious identify and those who did not. Although a relationship was not noted between religious coping styles and the psychological variables, significance was reported in the relationship between spiritual well-being and both psychological variables. Overall, it was found that individuals reporting higher levels of religiosity and spiritual well-being may also experience a reduction in mental and emotional illness.

Many researchers have demonstrated that spirituality plays a significant role in the lives of people, their thoughts, and behaviors. The effect of spirituality on mental health has been reviewed by Hodzic 2011). In order to make further advances in the field it is becoming increasingly important to (a) acknowledge the differences between the different religions; (b) develop context-specific definitions of spirituality, namely define spirituality in the context of a particular faith; and (c) construct the studies that will evaluate spirituality according to the context-specific measures.

Miller et al. (2011) qualitatively studied to gain a better understanding of the subjective experience of prayer with a sacred object within the context of a significant life stressor. Ten individuals, men and women, from the Catholic faith participated in semistructured interviews. Interview transcripts were read thoroughly and descriptive meaning units were extracted and analyzed for common themes. In their narratives participants revealed three overarching themes: (a) contextual information on the nature of the significant life event, (b) the spiritual architecture of prayer with a sacred object, and (c) a spiritual relationship with the sacred. The experience of prayer with a sacred object is a rich and integral aspect of these participants' spiritual lives that ultimately supports a sense of life meaning within the context of a significant life stressor.

With the onset and persistence of severe mental illness, consumers face major challenges to their spiritual values and belief systems. They experience disruptions to their sense of self and, as such, often dwell openly on concerns related to purpose and meaning in life. Assessing and intervening with respect to consumers' spiritual concerns is thus often important in recovery-oriented mental health practice. The purpose of this article is to consider how direct practitioners can help consumers address and develop their spiritual inclinations when they identified among their personal goals (Walsh, 2012).

\section{Research Methodology}

The paper employed a survey based research design and convenient sampling technique. The study was carried out in Delhi-NCR fast food joints which are known for authentic Indian vegetarian food also serves Navratras festivals dishes. A sample of 250 vegetarians was administered with an unstructured interview schedule after establishing rapport with them. Questions were adapted from standardized tool of Sell and Nagpal's The Subjective Wellbeing Inventory (1992). Before administering the questionnaires, they were assured of the confidentiality of their response. To get more clarified and verify to get generalized results, researchers administered focus group 
discussion and non-structured interviews in fast foods joints by taking their due permissions to interact. The six dimensions of interview schedule were: Mental mastery over self and environment, Rootedness and belongingness, Structural and cohesiveness aspect of family, Density of social network, Security in health and socioeconomic crisis and Expectation and Achievement Harmony. Besides above mentioned dimensions, also measured positive affect.

The age profile showed that majority belonged to the age group between 22 and 45 years of age. The educational profile indicates that 47 percent of the sample was post graduate. Nearly $68 \%$ of the respondents are working and 42 percent were non-working housewives and students. $60 \%$ of sample were pure vegetarians and $40 \%$ were vegetarians only during Navratas festivals. $75 \%$ of respondents kept fasts at least on last day of navratras festival if not all 9 days.

\section{Findings and Discussions}

As most people living in Delhi; NCR are young and working class with less time to cook for themselves at home with whole day fasting, $79 \%$ respondents reported they are happy and satisfied with not only with fast food joints services but also all categories hotels as every segment hotel has various new vegetarian dishes specifically for Navratras festivals which make them convenient to have get together and celebrate outside in the evenings. : Categories and Number of the respondents are show in Table $1.75 \%$ of the respondents reported that earlier it was difficult for them to have fast in Navratras as many youngsters felt like they had limited options to eat outside, but now more and more hotels have opted for vegetarian dishes not in Indian cuisine but also other cuisines and people are more opting for celebrations outside in hotels and fast food joints during Navratras festivals.

Today due to various discounts and deals available in all budgets hotels from two star to luxury segment and fast food restaurants like Halidiram, Bikanerwalaetc $91 \%$ respondents reported that they have enough options in eating joints for celebrating Navratras festivals and content with the services from hotel industry in Delhi NCR in comparison to past years and they don't feel today Navratras to be a hinderance in celebrating outside. A variety of options and orientation of hospitality sector can be observed by the availability of offers mentioned in a national daily newspaper article, ". During the nine day fast, restaurants are offering options instead of the regular 'saatvik'thaali. Royal China in the capital offers appetizers like Kung pao potato and honey lotus stem." We also serve green black mushroom, stuffed eggplant, rice and noodles and any vegetarian soup. All these dishes can be prepared without garlic. Even garlic-based sauce like garlic and
Schezwan are replaced by ginger chilli or soy chilli sauce," Royal China director Aashita Relan.

Another capital-based restaurant, Amsterdam Kitchen and Bar, serves all-day dining signature dishes like buckwheat nachos with tomato salsa and paprika dust, crispy buckwheat florets with spinach and potato with hot Salsa and much more. "We are a Europe-based restaurant. Purialoo is quite common during this festival. I wanted to do it in a different way. The dishes are basic and the ingredients are same as Indian cuisine for Navratri. But our food items have European taste and texture," said Amsterdam Kitchen and Bar head chef Abhinav Sharma. "Onion and garlic are not always important to prepare a dish. Zura-Bar, Bistro and Bakery in Gurgaon also serves European dishes like rosti potato with spinach ragout, vegetable skewer with spicy cilantro salsa, crusted cottage cheese steak with pepper colis and much more. Try Indian, European, Oriental flavours this Navratri (IANS, 2014).

Table 1: Categories and Number of the respondents

\begin{tabular}{|l|l|l|l|l|}
\hline Criteria & Women & Men & Children & Total \\
\hline Age & $26-43$ & $22-45$ & $12-17$ & \\
\hline $\begin{array}{l}\text { No. of } \\
\text { Respondents }\end{array}$ & 110 & 140 & 10 & 250 \\
\hline
\end{tabular}

The findings revealed that by large respondents of all age groups felt that there is up lift in their moods and increase in positivity and wellbeing as whole. As Indians place an importance to collectivist culture and their belongingness increases by this festival, it makes them closer to spiritual enlighten also.

It was found that positive affect was increased and respondents felt at least for these days they don't bother about their difficulties which may be ill health, low socio economic status and increasing stressful life of corporate life which is the normal routine life of New Delhi and National capita region of India. Positive affect appears to be made up of at least two distinct types of positive emotion that have been shown to be relatively independent (Watson and Tellegen, 1985; Watson, et al.1999), and that may have different influences on people's thinking and behavior (Fredrickson, 2001) Kunzmann, Stange and Jordon (2005) described the two types of positive affect as pleasant affect and positive involvement. Pleasant affect is defined as a positive emotional state involving relatively low arousal. Examples by respondents include feeling satisfied, content and happy. On the other hand positive involvement refers to higher-arousal states which were shown in responses such feeling inspired, alert and active during Navratras festivals by the respondents. The findings suggest that the customers taking vegetarian dishes and celebrating Navratras festivals were having intense emotions and gave response like "particularly excited about the festival environment" and feeling that "things are really going my way". 
Table 2: Measures of subjective well being

\begin{tabular}{|l|l|l|l|l|l|l|}
\hline Gender & $\begin{array}{l}\text { Mental mastery } \\
\text { over self and } \\
\text { environment }\end{array}$ & $\begin{array}{l}\text { Rootedness and } \\
\text { Belongingness }\end{array}$ & $\begin{array}{l}\text { Cohesive } \\
\text { aspect of } \\
\text { family }\end{array}$ & $\begin{array}{l}\text { Density of } \\
\text { Social } \\
\text { network }\end{array}$ & $\begin{array}{l}\text { Security in health } \\
\text { and socioeconomic } \\
\text { crisis }\end{array}$ & $\begin{array}{l}\text { Expectation and } \\
\text { Achievement } \\
\text { harmony }\end{array}$ \\
\hline Females & $33 \%$ & $43 \%$ & $43 \%$ & $35 \%$ & $42 \%$ & $40 \%$ \\
\hline Males & $27 \%$ & $40 \%$ & $33 \%$ & $30 \%$ & $40 \%$ & $31 \%$ \\
\hline $\begin{array}{l}\text { Total } \\
\text { responses }\end{array}$ & $60 \%$ & $83 \%$ & $76 \%$ & $75 \%$ & $82 \%$ & $71 \%$ \\
\hline
\end{tabular}

Overall 60\% respondents felt mental mastery over self and environment during Navratras festival by organizing and participating in festival rituals out of which $71 \%$ respondents feeling positive moods such as happiness, joy and love were women (Table 2). A number of researchers have found that women report experiencing more happiness and more intense positive emotions than men. The finding goes consonant with the various researches and the fact that mostly feast and festivals rituals of Navratras festivals are more celebrated by females than males (Diener et al., 1985). Observational studies of women's nonverbal behaviors affirm the greater expressiveness of women. For example, hundreds of studies show that women smile more frequently than men (LaFrance et al., 2003). Research (Baumgardner and Crothers, 2009) shows that incorporating five simple actions into our lives - connecting, being active, giving, learning and taking notice - improves our wellbeing and during Navratras festival, people do all these activities as this festival is considered to be very auspicious in every aspect of life which is considered to be big and starting of festival season in India.

$83 \%$ respondents reported Rootedness and belongingness during navratri festival by meeting their relatives and friends and eating out vegetarian dishes which was earlier not possible due to very less options available (Table 2).

$76 \%$ respondents reported that structural and cohesive aspect of family was increased during Navratras by family members performing rituals and customs of Navratri festival (Table 2).

$75 \%$ respondents reported the density of social network was increased during navratri and it was felt that during this week they have become more social and happiness increases (Table 2).

$82 \%$ respondents reported security in health and socio economic crisis as Navratri festivals customs includes wearing new clothes, all types of small and big purchasing auspicious and doing rituals dedicatedly build up their immunity even if they are having any health problems (Table 2).

$71 \%$ respondents reported expectation and achievement harmony is increased during festival and believe that things were really going their way and pleased about having accomplished something (Table 2).

\section{Conclusion}

Since ancient times India is celebrating many festivals and is known for its rich culture and heritage. In past, festivals were a medium for interaction and social cohesion for families, long distance relatives' communities and especially for women. It helped them to build and nurture their relationships and as women used to be indoors earlier it was the only medium for sharing their happiness, fear, love and other emotions and caring, and as an essential aspect of their wellbeing. But as times changed and due to globalizations and liberalization, more women got education and became active members of present workforce, individual's life has become time constraint and events for socialization reduced. In the stressful and fast pace life with limited time and less socializing activities, festival like Navratras which is nine days long indeed is even more important for today's generation subjective wellbeing and definitely with the changing times and fast pace life the hospitality industry has changed and is playing dynamic role for vegetarian customers of hospitality industry by bringing more options for their customers and indirectly enhancing their subjective wellbeing also.

\section{Suggestions for Future Research}

Due to very less information and research is oriented on this new area in hospitality industry, for future research there is enormous possibility to explore this topic for drawing concrete conclusions and implications for Life skill researchers, coaches and also hoteliers and individuals as general. Some of the suggestions include comparison with other groups, cross cultural and longitudinal research, large sample, coverage of more sectors, including more demographic variables.

\section{References}

Baumgardner S and Crothers M (2009) Positive Psychology. Pearson Publishers, New Delhi.

Bowen HE and Daniels MJ (2005) Does the music matter? Motivations for attending a music festival. Event Management 9(3): 155-164.

Brow DR, Carney JS, Parrish MS and Klem JL (2013) Assessing Spirituality: The Relationship between spirituality and Mental Health, Journal of Spirituality in Mental Health 15(2):107-122. 
Diener E, Emmons RA, Larsen RJ and Griffin S (1985) The Satisfaction with Life Scale. Journal of Personality Assessment 49: 71-75.

Diener E, Lucas RE and Oishi S (2002) Subjective well-being: The science of happiness and life satisfaction. In: Snyder CR and Lopez SJ (Eds.) Handbook of positive psychology. New York: Oxford University Press, Pp 63-73.

Fredrickson BL (2001) The role of positive emotions in positive psychology: The broaden-and-build theory of positive emotions. ,American Psychologist 56: 218-226. doi:10.1037/0003-066X.56.3.218.

Fredrickson BL and Losada MF (2005) Positive affect and the complex dynamics of human flourishing. American Psychologist 60(7): 78-686.

Gibson C and Connell J (2003) Bongo Fury: tourism, music and cultural economy at Byron Bay, Australia, 94: 164-187. doi: 10.1111/1467-9663.00247

Harrison N (22, June, 2014) The Power of Engagementat Music Festivals. Retrieved on 27 Oct 2014 from: http://positivepsychologyprogram.com/power-ofengagement-at-music-festival.

Hodzic M (2011) Spirituality and Mental Health: Current Research and Future Directions. Journal of Spirituality in Mental Health 13(4): 223-235.

IANS (September 25, 2014) Try Indian, European, Oriental Flavours This Navratri. NDTV Food. Retrieved on 21 June 2015 from: http://food.ndtv.com/food-drinks/try-indianeuropean-oriental-flavours-this-navratri-694095.

Kunzmann U, Stange A and Jordan J (2005) Positive affectivity and lifestyle in adulthood: Do you do what you feel? Personality and Social Psychology Bulletin 31: 574-588.

LaFrance M, Hecht MA and Paluck EL (2003) The contingent smile: A meta-Analysis of Sex Differences in Smiling 129(2): 305-334.
Mellor D, Hapidzal FH, The K, Ganesan R, Yeow J, Latif RA and Cummins R (2012) Spiritual Engagement and subjective wellbeing: A Naturalistic Investigation of the Thaipusam Festival. Journal of Spirituality in Mental Health 14(3): 209-225. DOI:10.1080/19349637.2012.697375

Miller LM, Gall TL and Corbeil L (2011) The Experience of Prayer with a Sacred Object within the context of significant Life Stress. Journal of Spirituality in Mental Health 13(4): 247-271.

Nagpal R and Sell H (1992) Assessment of subjective WellbeingThe Subjective Wellbeing Inventory (SUBI). Regional Health Paper, SEARO, No.24, World Health Organization, New Delhi.

Packer J and Ballantyne J (2010) The impact of music festival attendance on young people's psychological and social well-being. Psychology of Music 39(2): 164-181.

Seligman MEP and Csikszentmihalyi M (2000) Positive psychology: An introduction. American Psychologist 55: 5-14.

Seligman MEP (2011) Flourish: A visionary new understanding of happiness and wellbeing. New York:Simon and Schuster.

Stone AA and Mackie C (2014) Subjective Well Being: Measuring Happiness, Suffering, and Other Dimensions of Experience. Retreived on 29 Oct. 2014 from: http://www.nap.edu/openbook.php?record_id=18548

Walsh J (2012) Spiritual Interventions with consumers in Recovery from Mental Illness. Journal of Spirituality in Mental Health 14(4): 229-241.

Watson D and Tellegen A (1985) Toward a consensual structure of mood. Psychological Bulletin 98: 219-235.

Watson D, Wiese D, Vaidya J and Tellegen A (1999) The two general activation systems of affect: Structural findings, evolutionary considerations, and psychobiological evidence. Journal of Personality and Social Psychology, 76: $820-838$. 